\title{
Comparative Study of Cell Findings by Conventional Smear and Liquid-Based Cytology for Oral Exfoliative Cytology
}

\author{
Hiroyuki Seto', Masayuki Ukigaya ${ }^{2}$, Masaaki Suemitsu $^{2,3}$, Chieko Taguchi', \\ Hiroshi Yamamoto ${ }^{5}$, Chiori Nakamura ${ }^{1}$, Yoshikazu Nakayama ${ }^{1}$, \\ Mitsuko Nakayama ${ }^{4}$, Hidekuni Tanaka3, Kayo Kuyama ${ }^{2,3^{*}}$
}

${ }^{1}$ Nihon University Graduate School Dentistry at Matsudo, Oral Pathology, Chiba, Japan ${ }^{2}$ Department of Pathological Diagnosis, Nihon University Hospital at Matsudo, Chiba, Japan ${ }^{3}$ Department of Pathology, Nihon University School of Dentistry at Matsudo, Chiba, Japan ${ }^{4}$ Department of Community Oral Health, Nihon University School of Dentistry at Matsudo, Chiba, Japan ${ }^{5}$ Department of Oral Surgery, Nihon University School of Dentistry at Matsudo, Chiba, Japan

Email: *kuyama.kayo@nihon-u.ac.jp

How to cite this paper: Seto, H., Ukigaya, M., Suemitsu, M., Taguchi, C., Yamamoto, H., Nakamura, C., Nakayama, Y., Nakayama, M., Tanaka, H. and Kuyama, K. (2020) Comparative Study of Cell Findings by Conventional Smear and Liquid-Based Cytology for Oral Exfoliative Cytology. Open Journal of Stomatology, 10, 174-188.

https://doi.org/10.4236/ojst.2020.107017

Received: June 18, 2020

Accepted: July 13, 2020

Published: July 16, 2020

Copyright $\odot 2020$ by author(s) and Scientific Research Publishing Inc. This work is licensed under the Creative Commons Attribution International License (CC BY 4.0).

http://creativecommons.org/licenses/by/4.0/ (c) (i) Open Access

\begin{abstract}
Background: Liquid-based cytology (LBC) is a method of manufacturing cyto-diagnostic specimens. Improved accuracy is expected from standardizing specimen production and use of this method is rapidly spreading in oral cytology. On the other hand, LBC reportedly requires training to show peculiar cell findings compared to those of conventional smear cytology (CVC). Few studies have compared detailed cell findings for oral CVC and LBC. Objectives: The aim of this study was to compare cytological findings between CVC and LBC using cytomorphological image analysis. Materials and Methods: Cytological specimens were collected from 20 patients (negative for squamous neoplasia in 10, dysplasia in 5, squamous cell carcinoma in 5) and 5 controls of the tongue between January 2017 and December 2018. Two different preparation techniques were investigated cytomorphologically for CVC and LBC (BD Cytorich ${ }^{\mathrm{TM}}$ ). Results: LBC showed significantly higher cell numbers than CVC for all lesions. LBC-to-CVC ratio ranged from 9.52 (hyperkeratosis) to 1.87 (deep cells in oral squamous cell carcinoma (OSCC)). Nuclear area of normal, hyperkeratosis, and inflammation were significantly higher in LBC than those of CVC. Hyperchromasia was significantly more frequent with CVC than with LBC for hyperkeratosis, inflammation, dysplasia and OSCC. There was no significant difference in circularity between CVC and LBC among all lesions. Conclusion: Only one cytomorphological disadvantage was seen with LBC, in the form of decreased hyperchromasia. Further clarification of the advantages and disadvantages of LBC is needed, including management of precision and screening practices.
\end{abstract}




\section{Keywords}

Liquid-Based Cytology (LBC), Oral Exfoliative Cytology (EC), Conventional Smear Cytology (CVC), Oral Squamous Cell Carcinoma (OSCC)

\section{Introduction}

Oral squamous cell carcinoma (OSCC) is among the ten most common cancers around the world, with an estimated annual global incidence of 270,000 cases among men and 143,000 cases among women [1] [2]. Unfortunately, no significant reduction in the mortality rate of OSCC has been seen over the last 40 years, with approximately $50 \%$ of patients dying within 5 years of diagnosis [3]. In addition, leukoplakia and oral lichen planus (OLP) have been included as oral potentially malignant disorders (OPMDs) in the new World Health Organization (WHO) classification of head and neck tumors [4], defined as a clinical presentation carrying a risk of developing into cancer in the oral cavity. In addition, leukoplakias can transform into OSCCs in 1\%-10\% of cases and lichen planus in $5 \%$ of cases, depending on the attack site or grade of epithelial dysplasia observed [5].

Early detection of lesions by dentists leads to reduced OSCC mortality. Against this background, oral exfoliative cytology (EC) as a method of oral cancer screening has spread rapidly and improved in recent years. The principles of cytological screening programs have evolved from the initial observation of malignant cervical cells in wet fixed vaginal cytology preparations as described by Papanicolaou [6]. The application of oral EC for the evaluation of human oral lesions was initially described in 1963, but the utility of oral EC smears that can be obtained in a relatively non-invasive manner for the characterization of oncogenic risk in the oral cavity has not been reliably established to the same extent as for uterine cancers in gynecological examinations using Papanicolaou staining [7]. EC as a screening modality for oral cancers and precancers has not yet achieved the same success as that for cervical pathologies [8]. The method has been shown to offer low sensitivity in the diagnosis of oral cancer [9] [10]. The reported high rate of false-negative results has been attributed to several factors, including inadequate sampling, a high risk of procedural errors and the subjective interpretation of findings [11]. Over the years, oral EC methods have been evolved to the point of showing renewed promise in screening programs as well as the early assessment of suspicious oral lesions.

Since 1990, liquid-based cytology (LBC) has been considered as a method of improving slide quality and quantity compared to conventional smear cytology (CVC) [12]. Instead of an adequate smear, a suspension of cells is obtained, and several slides can be prepared. LBC has proven a reliable substitute for conventional smears in cervical screening to predict early malignant changes, in terms of both sensitivity and specificity and for minimizing the pitfalls associated with practical preparation of obtained cells [13] [14]. The utility of LBC has also been 
reported for other organs, such as the thyroid [15] and parathyroid [16]. In addition, LBC has potential as a screening tool for oral cancers and precancers. Moreover, with the improvements in cytological techniques that have resulted during the development of LBC, use of this approach as an auxiliary tool in the diagnosis of oral mucosal lesions has gained renewed interest [17] [18] [19]. That is, LBC provided clearer cytomorphological results, but at the cost of a loss of background information in high-grade lesions [20]. However, morphological data from the two methodologies were not shown in that study. Few comparative studies have provided detailed cell findings for oral CVC and LBC. To compare cytological findings, the present study performed microscopic observations and image analysis of CVC and LBC in oral mucosal disease.

\section{Materials and Methods}

\subsection{Subjects}

Oral EC specimens were obtained from Nihon University Hospital at Matsudo between January 2017 and December 2018. Twenty patients were divided into three subgroups: 10 patients classified as negative for intraepithelial lesion or malignancy (NILM) (comprising 5 patients with inflammation, 5 patients with hyperkeratosis); 5 patients with low-grade epithelial dysplasia (dysplasia); and 5 patients with malignant lesions (OSCC, well-differentiated type). Details of cases are shown in Table 1 . The 20 patients comprised 10 men (mean age, $55.1 \pm 18.9$ years) and 10 women (mean age, $63.9 \pm 16.5$ years). Biopsy was performed after smear collection to confirm the histological diagnosis.

All pathological lesions were identified on the edge of the tongue. In control subjects (normal, $\mathrm{n}=5$, mean age $36.0 \pm 13.7$ years), smears were obtained by brushing from the edge of the tongue from healthy volunteers. Exclusion criteria included: presence of any systemic illness or use of any medication 2 years prior to the study; presence of habits that were considered likely to affect to the oral mucosa (drinking, smoking, or heavy use, more than 10 times a day, of mouthwash); Candida infection; or use of dentures/orthodontic appliances.

Informed consent was obtained from all individuals prior to inclusion in the study. All procedures in studies involving human participants were performed in accordance with the ethical standards of the Committee on Studies Involving Human Beings of Nihon University School of Dentistry at Matsudo (EC-15-14-033-1) and with the 1964 Declaration of Helsinki and its later amendments.

\subsection{Oral Exfoliative Cytology}

\section{1) Cell collection}

All cell collection was performed by the same skilled oral surgeon. Specimens were collected using a cell collecting brush (Orcellex ${ }^{\circledR}$ brush RT; Becton, Dickinson and Company, Tokyo, Japan) [21]. Each brush was rotated at the lesion 10 times. The split sample method was used for specimen preparation of all cytological samples. 
Table 1. Details of study subjects.

\begin{tabular}{|c|c|c|c|c|c|}
\hline Case & Age (years) & Sex & Location & Cytological diagnosis & Histopathological diagnosis \\
\hline 1 & 25 & Male & Tongue $^{1}$ & $\mathrm{NILM}^{2}$ & $--^{5}$ \\
\hline 2 & 23 & Male & Tongue $^{1}$ & NILM $^{2}$ & $--^{5}$ \\
\hline 3 & 31 & Male & Tongue $^{1}$ & NILM $^{2}$ & $--^{5}$ \\
\hline 4 & 48 & Female & Tongue $^{1}$ & NILM $^{2}$ & - - ${ }^{5}$ \\
\hline 5 & 53 & Female & Tongue $^{1}$ & NILM $^{2}$ & $--^{5}$ \\
\hline 6 & 24 & Male & Tongue $^{1}$ & NILM $^{2}$ & Inflammation \\
\hline 7 & 63 & Female & Tongue $^{1}$ & NILM $^{2}$ & Inflammation \\
\hline 8 & 83 & Female & Tongue $^{1}$ & NILM $^{2}$ & Inflammation \\
\hline 9 & 35 & Male & Tongue $^{1}$ & NILM $^{2}$ & Inflammation \\
\hline 10 & 44 & Female & Tongue $^{1}$ & NILM $^{2}$ & Inflammation \\
\hline 11 & 76 & Male & Tongue $^{1}$ & NILM $^{2}$ & Hyperkeratosis \\
\hline 12 & 84 & Male & Tongue $^{1}$ & NILM $^{2}$ & Hyperkeratosis \\
\hline 13 & 88 & Female & Tongue $^{1}$ & NILM $^{2}$ & Hyperkeratosis \\
\hline 14 & 36 & Female & Tongue $^{1}$ & NILM $^{2}$ & Hyperkeratosis \\
\hline 15 & 41 & Male & Tongue $^{1}$ & NILM $^{2}$ & Hyperkeratosis \\
\hline 16 & 64 & Male & Tongue $^{1}$ & OSIL $^{3}$ & Dysplasia \\
\hline 17 & 61 & Female & Tongue $^{1}$ & OSIL $^{3}$ & Dysplasia \\
\hline 18 & 70 & Female & Tongue $^{1}$ & OSIL $^{3}$ & Dysplasia \\
\hline 19 & 54 & Male & Tongue $^{1}$ & OSIL $^{3}$ & Dysplasia \\
\hline 20 & 60 & Female & Tongue $^{1}$ & OSIL $^{3}$ & Dysplasia \\
\hline 21 & 71 & Male & Tongue $^{1}$ & OsCC $^{4}$ & Squamous cell carcinoma \\
\hline 22 & 52 & Male & Tongue $^{1}$ & OSCC $^{4}$ & Squamous cell carcinoma \\
\hline 23 & 50 & Male & Tongue $^{1}$ & $\mathrm{OSCC}^{4}$ & Squamous cell carcinoma \\
\hline 24 & 56 & Female & Tongue $^{1}$ & OSCC $^{4}$ & Squamous cell carcinoma \\
\hline 25 & 78 & Female & Tongue $^{1}$ & $\mathrm{OSCC}^{4}$ & Squamous cell carcinoma \\
\hline
\end{tabular}

${ }^{1}$ Edge of the tongue; ${ }^{2}$ Negative for intraepithelial neoplasia or malignancy; ${ }^{3}$ Oral squamous intraepithelial lesion; ${ }^{4}$ Oral squamous cell carcinoma; ${ }^{5}$ No biopsy was performed.

\section{2) Specimen preparation}

Conventional smears were prepared from the brush, fixed in 95\% ethanol for 3 hours and subsequently stained by routine Papanicolaou (PAP) staining. PAP staining dyes the cytoplasm into light green/blue, orange, and red by several substances with different molecular weights. After conventional smear preparation, the brush containing the remaining cells was immersed in a preservative vial (Cytorich ${ }^{\mathrm{TM}}$ red; BD). Fixation was performed for over 30 minutes. Specimen preparation for LBC (BD Cytorich ${ }^{\mathrm{TM}}$ as SurePath ${ }^{\mathrm{TM}}$ manual method; BD) followed the instructions from the manufacturer. In short, the preservative vial was centrifuged at $2000 \mathrm{rpm}$ for 5 minutes, then the supernatant was discarded. 
After adding $500 \mathrm{ml}$ of purified water, the sediment was stirred. About $250 \mathrm{~mL}$ of sediment was dispensed onto a pre-coated slide with a settling chamber and left to stand for 10 minutes. After inverting the slide tray and discarding the solution, the slide was washed twice with $100 \%$ ethanol. The slide tray was then turned upside-down for no more than $1 \mathrm{~min}$ to remove excess alcohol. Thereafter, PAP staining was performed.

\section{3) Cytological and pathological diagnosis}

Cytological diagnosis was performed under microscopy (Olympus BX51; Olympus, Tokyo, Japan) by at least one cyto-screener for each specimen. After that, two or more dentists board certified trainer of oral cytology by the Japan Society of Clinical Cytology. Each cytological specimen was then observed for cytological findings including thickness of the smear, cellular distribution, resolution/clarity of cells, cellular staining characteristics and the presence of unsatisfactory background/artifacts and cytoplasm/nuclear form. Definitive pathological diagnosis was made by two or more oral pathologists certified by the Japan Society of Pathology. The criteria for definitive diagnoses followed the criteria published by the WHO [4].

\section{4) Cytomorphological methods}

Using a marking pen, a line was drawn across the center of each specimen. Ten discontinuous fields across the middle diameter of each preparation were evaluated using a $\times 40$ objective lens. Only well-visualized squamous cells were counted. The average cell count from the 10 fields $(\times 40)$ was measured. An average of $\geq 50$ cells/case was required for cytomorphological analysis. Selection of atypical squamous cells was performed by two cyto-screeners and two dentists specializing in oral cytology. Dysplastic cells of OSCC were divided into deep and superficial layers. After selecting about 50 cells/case, pictures were taken using a digital camera (Olympus DP74; Olympus), and cytomorphological analyses were performed using imaging software for microscopy (cellSens ${ }^{\circledR}$ software; Olympus). Cell number and nuclear findings (area, hyperchromasia, irregularity, and circularity) were quantified.

\subsection{Statistical Analysis}

All statistical analyses were performed using SPSS for Windows version 14. OJ (IBM, Tokyo, Japan). Statistical analyses were performed using the Wilcoxon signed-rank test, the Kruskal-Wallis test and Steel-Dwass test. Values of $\mathrm{p}<0.05$ were considered statistically significant.

\section{Results}

\subsection{Cytological Findings}

Representative cytological pictures are shown in Figure 1 and Figure 2. A significantly larger number of superficial cells was observed with LBC (Figures 1(a2)-(d2)) than with CVC (Figures 1(a1)-(d1)) in all cases. Squamous cells in LBC formed clusters in the superficial layer, middle layer and deep layer. 
Conventional smear cytology
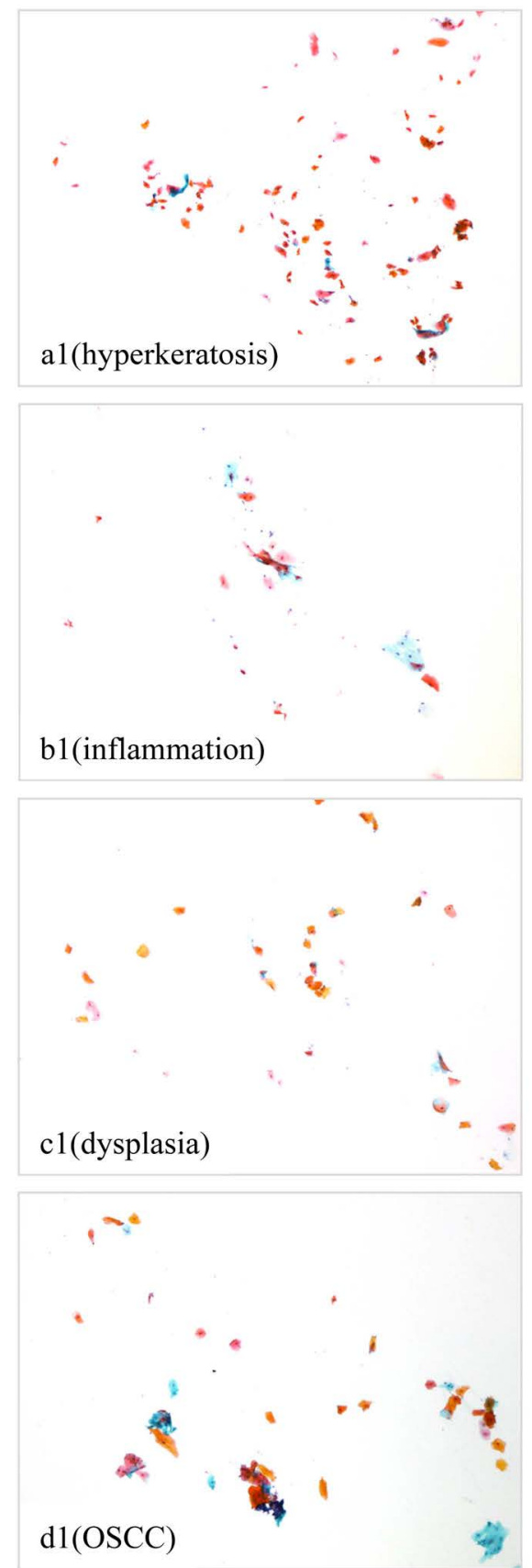

Liquid based cytology
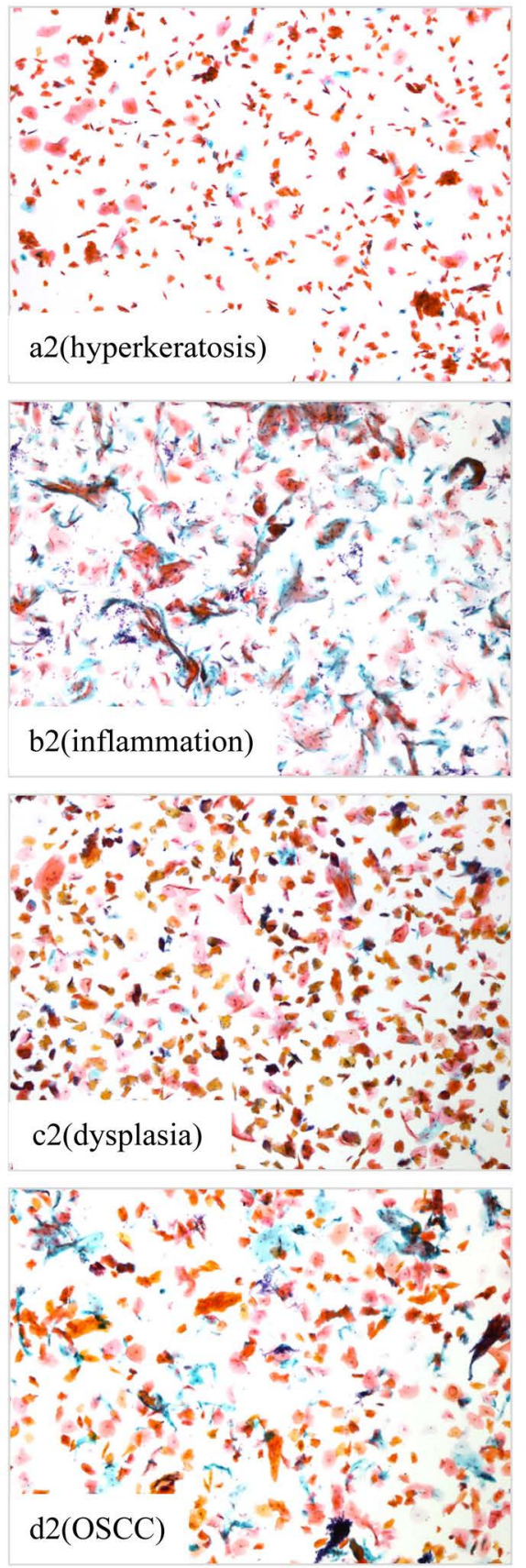

Figure 1. Appearance of cell clusters for all lesions by conventional smear and liquid based cytology $(\times 4$, Papanicolaou staining, a: hyperkeratosis, b: inflammation, c: dysplasia, d: squamous cell carcinoma). (a1)-(d1) Small number of cell clusters shown in conventional smear cytology; (a2)-(d2) Plenty of cell clusters appeared in liquid based cytology.

Slight intussusception was apparent in LBC but did not impact cell observations. In the background, inflammatory cells, necrotic debris and erythrocytes were decreased in LBC. In cases of hyperkeratosis, keratin debris and orthokeratinized squamous cells were mainly observed (Figure 1(a1), Figure 1(a2)). With CVC, keratinized superficial cells with keratohyaline granules and keratin debris formed 


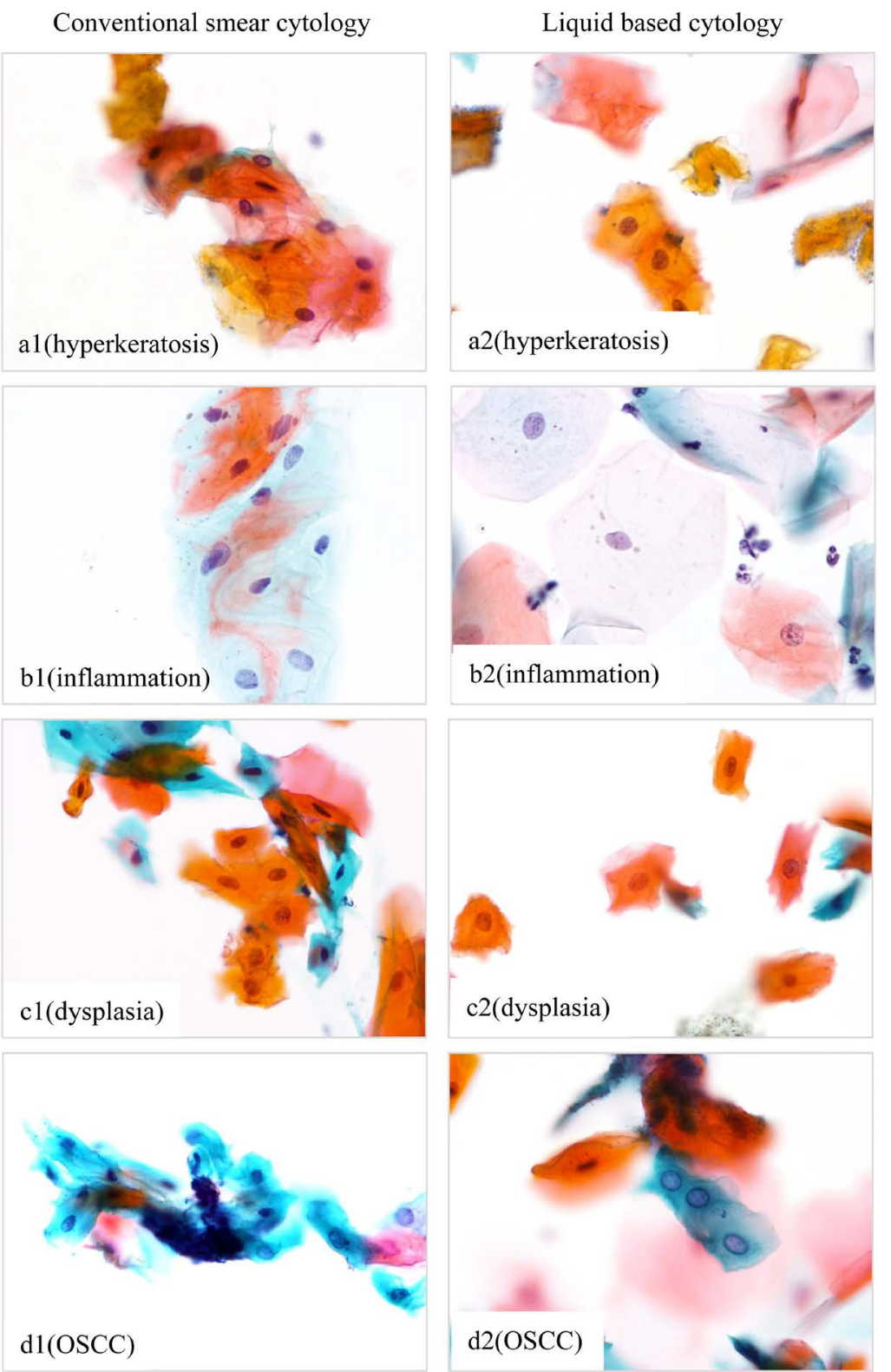

Figure 2. Presentative cytological findings for all lesions by conventional smear and liquid based cytology ( $\times 60$, Papanicolaou staining, a: hyperkeratosis, b: inflammation, c: dysplasia, d: squamous cell carcinoma). (a1)-(d1) Pyknosis in shown in hyperkeratosis, dysplasia and deep typical cells in squamous cell carcinoma by conventional smear cytology; (a2)-(d2) Nuclear structure is clearer for all lesions by liquid based cytology than conventional smear cytology.

a clustered appearance. Slight thickening of nuclear contours, pyknosis and no increase in nuclear/cytoplasm ratio were observed (Figure 2(a1)). With LBC, nuclei showed slightly more irregular contours, clear nuclear structures and fine chromatin distribution (Figure 2(a2)). In inflammation cases, non- or para-keratinized cells with mild nuclear swelling and keratin debris were observed intermingled in both methods (Figure 1(b1), Figure 1(b2)). With LBC, each cell was isolated and showed increased transparency of cytoplasm and clear nuclear structures 
(Figure 2(b2)). In cases of dysplasia, the difference in the number of cells collected between LBC and CVC is clear (Figure 1(c1), Figure 1(c2)). Keratinized dysplastic cells showed cytoplasmic thickening with staining by deep orange $\mathrm{G}$, nuclei with irregular contours, irregular chromatin distribution, pyknosis and an increased N/C ratio with CVC (Figure 1(c1)). With LBC, keratinized dysplastic cells appeared solitary with a torn appearance of cytoplasmic margins, but brightness was higher than in CVC. Nuclear structure was clearer with LBC than with CVC (Figure 1(c2)). In OSCC, diversity of cytoplasmic staining was observed in both methods (Figure 1(d1), Figure 1(d2)). Deep atypical cells and superficial atypical cells were appeared intermingled in CVC (Figure 1(d1)), and the two types of atypical cells each formed small clusters in LBC (Figure 1(d2)). Thickened cytoplasm with deep blue coloration, deep dysplastic cells with dense chromatin, thickening of nuclear contours and pyknosis were observed with CVC (Figure 1(d1)). Conversely, moderate thickening of nuclear contours and slight nuclear swelling was shown with LBC, but nuclear transparency was increased, and circularity was maintained (Figure 1(d2)).

\subsection{Cytomorphological Analyses}

\section{1) Comparisons between lesions}

Results of nuclear cytomorphological analysis with CVC are shown in Table 2. Nuclear area was significantly lower in normal $\left(35.8 \mathrm{um}^{2}\right)$ and hyperkeratosis $\left(35.7 \mathrm{um}^{2}\right)$ cases than in other lesions. Inflammation (175.8) cases showed higher hyperchromasia than normal (91.3), hyperkeratosis (87.1) or dysplasia cases (80.7), and OSCC (superficial cells, 102.8) showed higher hyperchromasia than those of all other lesions. Irregularity was significantly lower in normal cases (11.0) than in all lesions except OSCC (superficial cells, 11.7). No significant difference in irregularity was seen between dysplasia (12.8) and either layer of OSCC. Regarding circularity, OSCC (deep cells, 0.72) displayed greater irregularity than hyperkeratosis $(0.65)$ or dysplasia $(0.66)$.

Results of LBC are shown in Table 3. Nuclear area was larger for inflammation $\left(69.6 \mathrm{um}^{2}\right)$ than for all other lesions. Inflammation (156.3) cases showed higher

Table 2. Results of nuclear cytomorphological analysis for conventional cytology.

\begin{tabular}{|c|c|c|c|c|c|c|c|c|c|c|c|c|c|c|c|c|c|c|c|}
\hline \multirow[b]{3}{*}{ Normal } & \multicolumn{4}{|c|}{ Area $\left(\mathrm{um}^{2}\right)$} & \multicolumn{5}{|c|}{ Hyperchromasia } & \multicolumn{5}{|c|}{ Irregularity } & \multicolumn{5}{|c|}{ Circularity } \\
\hline & \multirow{2}{*}{$\begin{array}{l}\text { Median } \\
35.8\end{array}$} & \multicolumn{3}{|c|}{ Range } & \multirow{2}{*}{\multicolumn{2}{|c|}{ Median }} & \multicolumn{3}{|c|}{ Range } & \multicolumn{2}{|c|}{ Median } & \multicolumn{3}{|c|}{ Range } & \multicolumn{2}{|c|}{ Median } & \multicolumn{3}{|c|}{ Range } \\
\hline & & 32.7 & - & 42.0 & & & 88.2 & - & 94.1 & 11.0 & & 10.1 & - & 12.0 & 0.71 & & 0.67 & & 0.82 \\
\hline Hyperkeratosis & 35.7 & 29.1 & - & 41.5 & 87.1 & & 80.1 & - & 94.2 & 9.5 & $a *$ & 8.5 & 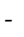 & 11.4 & 0.65 & $a * *$ & 0.60 & & 0.76 \\
\hline Inflammation & $56.7^{a \star *, b * *}$ & 51.2 & - & 69.1 & 175.8 & $a * *, b * *$ & 157.5 & - & 186.8 & 19.2 & $a * *, b * *$ & 14.4 & - & 20.5 & 0.70 & & 0.63 & & 0.75 \\
\hline Dysplasia & $48.9^{a \star, b * *}$ & 35.5 & - & 57.9 & 80.7 & $c * *$ & 71.3 & - & 99.9 & 12.8 & $a *, b * *, c * *$ & 10.5 & - & 14.8 & 0.66 & $a *$ & 0.59 & & 0.76 \\
\hline OSCC (deep cells) & $51.3^{a * *, b * *}$ & 37.0 & - & 61.3 & 142.2 & $\mathrm{a} * *, \mathrm{~b} * *, \mathrm{c} * *, \mathrm{~d} * *$ & 124.4 & - & 157.1 & 15.6 & $a * *, b * *$ & 13.0 & - & 17.1 & 0.72 & $\mathrm{~b} *, \mathrm{~d} *$ & 0.66 & & 0.79 \\
\hline OSCC (superficial cells) & $53.1^{a \star *, b * *}$ & 43.7 & - & 57.2 & 102.8 & $\mathrm{a} * *, \mathrm{~b} * *, \mathrm{c} * *, \mathrm{~d} * *, \mathrm{e} * *$ & 98.9 & - & 137.8 & 11.7 & $c * x$, ex & 8.6 & - & 16.5 & 0.68 & & 0.64 & - & 0.76 \\
\hline
\end{tabular}

a: vs normal; b: vs hyperkeratosis; c: vs inflammation; d: vs dysplasia; e: vs OSCC (deep cells). ${ }^{*} \mathrm{p}<0.05 ;{ }^{* *}$ p $<0.01$ (the Kruskal-Wallis test and Steel-Dwass test). 
Table 3. Results of nuclear cytomorphological analysis for liquid-based cytology.

\begin{tabular}{|c|c|c|c|c|c|c|c|c|c|c|c|c|c|c|c|c|c|c|c|c|}
\hline \multirow{2}{*}{ Normal } & \multicolumn{5}{|c|}{ Area $\left(\mathrm{um}^{2}\right)$} & \multicolumn{5}{|c|}{ Hyperchromasia } & \multicolumn{5}{|c|}{ Irregularity } & \multicolumn{5}{|c|}{ Circularity } \\
\hline & \multicolumn{2}{|c|}{ Median } & \multicolumn{3}{|c|}{ Range } & \multicolumn{2}{|r|}{ Median } & \multicolumn{3}{|c|}{ Range } & \multicolumn{2}{|c|}{ Median } & \multicolumn{3}{|c|}{ Range } & \multicolumn{2}{|c|}{ Median } & \multicolumn{3}{|c|}{ Range } \\
\hline Hyperkeratosis & 49.5 & & 41.7 & - & 56.0 & 71.5 & $a * *$ & 59.5 & - & 77.2 & 9.9 & $a * *$ & 8.2 & - & 11.2 & 0.67 & $a * *$ & 0.54 & - & 0.78 \\
\hline Inflammation & 69.6 & $a * *, b * *$ & 51.6 & - & 87.1 & 156.3 & $a * *, b * *$ & 146.1 & - & 184.1 & 16.4 & $a * *, b * *$ & 14.3 & - & 22.3 & 0.80 & $b *$ & 0.70 & - & 0.81 \\
\hline Dysplasia & 50.3 & $c * *$ & 46.1 & - & 55.0 & 76.9 & $a * *, c * *$ & 61.5 & - & 84.1 & 14.4 & $b * *$ & 11.1 & - & 18.1 & 0.70 & $a *$ & 0.60 & - & 0.84 \\
\hline OSCC (deep cells) & 48.8 & $c * *$ & 44.0 & - & 62.4 & 97.3 & $\mathrm{a} * *, \mathrm{~b} * *, \mathrm{c} * *, \mathrm{~d} * *$ & 88.3 & - & 116.8 & 18.5 & $a * *, b * *, d * *$ & 17.0 & - & 21.1 & 0.77 & $b *$ & 0.69 & - & 0.84 \\
\hline OSCC (superficial cells) & 49.6 & $c * *$ & 38.0 & - & 64.2 & 71.2 & $a * *, c * x, e * *$ & 55.7 & - & 87.8 & 13.3 & $b * x, c * *, e * *$ & 11.8 & - & 17.9 & 0.76 & & 0.65 & - & 0.83 \\
\hline
\end{tabular}

a: vs normal; b: vs hyperkeratosis; c: vs inflammation; d: vs dysplasia; e: vs OSCC (deep cells). ${ }^{\star} \mathrm{p}<0.05 ;{ }^{* *} \mathrm{p}<0.01$ (the Kruskal-Wallis test and Steel-Dwass test).

hyperchromasia than normal (122.2) and hyperkeratosis (71.5), dysplasia (76.9) and both layers of OSCC. No significant difference in irregularity was seen between dysplasia (14.4) and OSCC (superficial cells, 13.3). No significant difference in circularity was seen between OSCC (superficial cells, 0.76 ) and all other lesions.

\section{2) Comparison between sample preparation methods}

Results of cytomorphological analysis are shown in Table 4. In all 5 groups, LBC yielded significantly higher cell numbers than CVC. Comparing among cases, hyperkeratosis showed the lowest number of cells among all 5 groups with both CVC (21.27) and LBC (202.40). The LBC-to-CVC ratio for cell numbers ranged from 9.52 for hyperkeratosis to 1.87 for deep cells in OSCC. For nuclear area, the most prominent nuclear swelling was shown in inflammation with both CVC (57.99) and LBC (74.95), and cells were significantly larger with LBC than with CVC for normal, hyperkeratosis, and inflammation cases. As for hyperchromasia, denser, darkish changes were seen for inflammation with both CVC (173.59) and LBC (157.36), next to deep cells in CVC, and hyperkeratosis, inflammation, dysplasia and OSCC cases showed significantly bigger cells with LBC than with CVC. Irregularity was prominent in inflammation (23.64) and OSCC (deep cells, 18.18) with LBC, and cells of normal mucosa and OSCC (deep cells) were significantly bigger with LBC than with CVC. No significant difference in circularity was seen between CVC and LBC among all 5 groups.

\section{Discussion}

Oral EC is an approach for harvesting cells from the oral mucosa [22], and its adoption has been delayed due to variations in accuracy. In recent years, the debate has been further complicated by the spread of LBC [23] [24] [25].

In comparisons of oral biopsy and EC, EC appears to better reflect early epithelial atypia in oral premalignant and early malignant lesions [26] [27]. Furthermore, in 1973, Allegra et al. [23] published the largest review analysis of previous studies, including 6448 samples. That study showed $97.3 \%$ sensitivity for oral EC, with only two false-negative cases. Conversely, high false-positive rates have been reported for oral mucosal lesions, at 63.9\% [28] and 87\% [29]. 
Table 4. Comparison of cytomorphological results between conventional and liquid-based cytology of all lesions.

\begin{tabular}{|c|c|c|c|c|c|c|c|c|}
\hline \multirow{2}{*}{$\begin{array}{c}\text { Histopathological } \\
\text { diagnosis }\end{array}$} & \multirow{2}{*}{$\begin{array}{l}\text { Preparation } \\
\text { method }\end{array}$} & & & \multicolumn{5}{|c|}{ Nuclear findings } \\
\hline & & & & Cell number ${ }^{3}$ & Area $\left(\mathrm{um}^{2}\right)$ & Hyperchromasia & Irregularity & Circularity \\
\hline \multirow[t]{4}{*}{ Normal } & $\mathrm{CVC}$ & & $\mathrm{Ave}^{1}$ & 27.53 & 38.04 & 90.33 & 11.09 & 0.75 \\
\hline & & & $\mathrm{SD}^{2}$ & 2.77 & 7.82 & 23.80 & 3.09 & 0.19 \\
\hline & LBC & & $\mathrm{Ave}^{1}$ & 248.60 & 50.05 & 125.33 & 12.56 & 0.76 \\
\hline & & & $\mathrm{SD}^{2}$ & 19.04 & 3.83 & 21.34 & 2.81 & 0.01 \\
\hline \multirow[t]{4}{*}{ Hyperkeratosis } & $\mathrm{CVC}$ & & $\mathrm{Ave}^{1}$ & 21.27 & 35.21 & 88.27 & 9.97 & 0.66 \\
\hline & & & $\mathrm{SD}^{2}$ & 4.86 & 8.62 & 12.19 & 2.40 & 0.10 \\
\hline & LBC & & $\mathrm{Ave}^{1}$ & 202.40 & 49.55 & 68.91 & 10.61 & 0.67 \\
\hline & & & $\mathrm{SD}^{2}$ & 35.00 & 9.05 & 13.76 & 4.07 & 0.16 \\
\hline \multirow[t]{4}{*}{ Inflammation } & $\mathrm{CVC}$ & & $\mathrm{Ave}^{1}$ & 29.93 & 57.99 & 173.59 & 18.15 & 0.69 \\
\hline & & & $\mathrm{SD}^{2}$ & 8.03 & 15.20 & 15.48 & 5.04 & 0.09 \\
\hline & LBC & & $\mathrm{Ave}^{1}$ & 281.20 & 74.95 & 157.36 & 23.64 & 0.77 \\
\hline & & & $\mathrm{SD}^{2}$ & 59.56 & 26.39 & 27.95 & 27.14 & 0.10 \\
\hline \multirow[t]{4}{*}{ Dysplasia } & $\mathrm{CVC}$ & & $\mathrm{Ave}^{1}$ & 25.53 & 49.56 & 85.18 & 13.69 & 0.65 \\
\hline & & & $\mathrm{SD}^{2}$ & 9.24 & 17.73 & 21.96 & 4.57 & 0.14 \\
\hline & LBC & & $\mathrm{Ave}^{1}$ & 236.47 & 50.03 & 76.11 & 15.36 & 0.70 \\
\hline & & & $\mathrm{SD}^{2}$ & 62.00 & 7.87 & 24.79 & 4.81 & 0.17 \\
\hline \multirow[t]{8}{*}{ OSCC } & CVC & Deep cells & $\mathrm{Ave}^{1}$ & 41.33 & 53.73 & 116.82 & 13.41 & 0.70 \\
\hline & & & $\mathrm{SD}^{2}$ & 14.59 & 18.55 & 26.62 & 6.28 & 0.15 \\
\hline & LBC & & $\mathrm{Ave}^{1}$ & 312.27 & 54.52 & 75.03 & 14.53 & 0.72 \\
\hline & & & $\mathrm{SD}^{2}$ & 46.87 & 20.28 & 25.79 & 3.56 & 0.12 \\
\hline & $\mathrm{CVC}$ & Superficial cells & $\mathrm{Ave}^{1}$ & 17.23 & 48.32 & 138.17 & 15.16 & 0.74 \\
\hline & & & $\mathrm{SD}^{2}$ & 3.48 & 15.40 & 23.89 & 3.79 & 0.11 \\
\hline & LBC & & $\mathrm{Ave}^{1}$ & 32.15 & 53.02 & 98.82 & 18.18 & 0.75 \\
\hline & & & $\mathrm{SD}^{2}$ & 6.49 & 15.37 & 29.07 & 4.55 & 0.11 \\
\hline
\end{tabular}

: $\mathrm{p}<0.05$ (Wilcoxon signed-rank test). Bigger values are colored in gray. ${ }^{1}$ Average; ${ }^{2}$ Standard deviation; ${ }^{3}$ Total cell number/5 HPF.

To summarize previous reports, the popularity of oral EC remains low and restricted due to difficulties with cell harvesting and differing methods of sample preparations (EC or LBC), in addition to accuracy issues [25].

Whereas EC reveals morphophysiological alterations [30] in squamous cells such as dirtiness of the smear and changes in nuclear size, all of which may be used to aid presumptive diagnosis of the oral mucosa [31], Superficial cells in leukoplakia or OLP with dysplasia and OSCCs without ulceration show weak atypia [32]. In the present study, no distinction between dysplasia and other lesions was observed by neither CVC n1or LBC. In addition, changes in nuclear findings due to increased grade of oral mucosal dysplasia are smaller than those seen on examinations of the uterine cervix, leading to false-negative diagnoses 
[32]. Concerning OSCC (superficial cells), hyperchromasia in CVC is significantly higher than dysplasia, but no significant difference in LBC. Overall, inflammatory cytological changes were more prominent compare to other lesion in both methods, and this was speculated to have contributed to decreased accuracy.

Kahm [33] described false results as potentially attributable to collection of only surface epithelial cells, as characteristic cellular pathological changes may not extend to the surface on conventional EC. In addition, the great variation in technical quality of cytological smears increases the chance for diagnostic failure on microscopic examination.

Compared to CVC, LBC reduced false-negative results [34]. In addition, LBC offers significant advantages, particularly the good depiction of cell morphology and staining, and clean background [1] [35] [36], but specific morphological descriptions have been lacking. On the contrary, no superiority was observed for LBC when the form of clinical growth was exophytic or where the clinical growth pattern was leukoderma in the uterine cervix [37]. In the present study, LBC also yielded markedly higher numbers of cells, even in lesions showing hyperkeratosis. Regarding comparisons of cell morphology, nuclear findings of various organs have most commonly been reported. In parathyroid lesions, LBC showed variable degrees of cellularity, similar nuclear features, but smaller nuclei, and better-preserved cell borders [16]. In lymph nodes, the nuclear and cytoplasmic architecture were better appreciated with LBC [38]. Accordingly, reports on the benefits of LBC for oral mucosal lesions have been scattered [17] [18] [19], but studies comparing oral cell morphology between CVC and $\mathrm{LBC}$ remain scarce. Sharma et al. [39] described thinner smears on LBC with uniform distribution of cellular material along with a clearer background and better details of cellular morphology, such as nuclear hyperchromasia and bi- or multinucleation in oral lesions, but only 5 cases were used. Oral EC needs precision management, and accumulation of characteristic features with the conventional method and LBC is an urgent matter.

The present study observed thin smears with homogeneous cell distribution, abundant cellularity and clear backgrounds in LBC. Cells also showed crispier outlines and good quality of staining. In addition, cell clumps were formed by heavier atypical cells and stratified squamous epithelium with natural sedimentation due to gravity. These two points appear useful for organizing information at the time of screening. Conversely, no superiority was observed for LBC, where the clinical growth style was exophytic or where the clinical growth pattern showed leukoderma in the uterine cervix [37]. In the present study, LBC also obtained a markedly greater number of cells even in lesions showing hyperkeratosis. The present results suggest that diagnostic precision would be improved with LBC. On the other hand, on screening for decreased hyperchromasia, the denser nuclear staining would presumably lead to underdiagnosis. This was consistent with the present result that hyperchromasia is not useful for identifying dysplasia under LBC. 
Navone et al. [1] reviewed the literature for the efficacy and efficiency of LBC and CVC in the early diagnosis of OSCCs and OPMDs. They concluded that although CVC helps in screening, LBC yielded better results, enhancing both sensitivity and specificity and providing material for further investigation. In conclusion, both LBC and CVC appear diagnostically reliable, with LBC showing overall improvements in sample preservation, specimen adequacy, visualization of cell morphology and reproducibility in oral lesions. These tendencies were similar to a previous description [35]. Only one cytomorphological disadvantage was apparent, in the decrease of hyperchromasia with LBC, but more issues remain to be clarified, including precision management and practices for screening peculiar to LBC. This study is limited in the number of cases, so there is a limitation to the conclusion. The number of cases should be increased, and further studies should be conducted.

\section{Conclusions}

The following could be concluded in the present study:

1) LBC showed significantly higher cell numbers than CVC for all lesions.

2) Hyperchromasia was significantly more frequent with CVC than with $L B C$ for hyperkeratosis, inflammation, dysplasia and OSCC.

3) There was no significant difference in circularity between CVC and LBC among all lesions.

4) Only one cytomorphological disadvantage was seen with LBC, in the form of decreased hyperchromasia.

\section{Acknowledgements}

This work was supported by JSPS KAKENHI Grant Number 18K07000.

\section{Conflicts of Interest}

The authors declare no conflicts of interest regarding the publication of this paper.

\section{References}

[1] Navone, R., Pentenero, M. and Gandolfo, S. (2011) Liquid-Based Cytology in Oral Cavity Squamous Cell Cancer. Current Opinion in Otolaryngology \& Head and Neck Surgery, 19, 77-81. https://doi.org/10.1097/MOO.0b013e328343af10

[2] Franceschi, S., Barzan, L. and Talamini, R. (1997) Screening for Cancer of the Head and Neck: If Not Now, When? Oral Oncology, 33, 313-316. https://doi.org/10.1016/S1368-8375(97)00034-1

[3] Howaldt, H.P., Frenz, M. and Pitz, H. (2005) Results from DÖSAK Observational Studies. In: Pape, H.D., Ganzer, U. and Schmitt, G., Eds., Carcinoma of the Oral Cavity and Oropharynx, Springer-Verlag, Berlin, Heidelberg, 173-182. https://doi.org/10.1007/978-3-642-84971-8_19

[4] Reibel, J., Gale, N., Hille, J., Hunt, J., Lingen, M., Muller, S., Sloan, P., Tilakaratne, W., Westra, W., Williams, M., Vigneswaran, N., Fatani, H., Odell, E. and Zain, R. (2017) Oral Potentially Malignant Disorders and Oral Epithelial Dysplasia. In 
El-Naggar, A.K., Chan, J.K.C., Grandis, J.R., Takata, T. and Slootweg, P.J., Eds., WHO Classification of Head and Neck Tumours, 4th Edition, IARC Press, Lyon, 112-115.

[5] Sawaf, M.H., Ouhayoun, J.P. and Forest, N. (1991) Cytokeratin Profiles in Oral Epithelial: A Review and a New Classification. Journal de Biologie Buccale, 19, 187-198.

[6] Smith, J.H.F. (2011) Cytology, Liquid-Based Cytology and Automation. Best Practice \& Research Clinical Obstetrics \& Gynaecology, 25, 585-596. https://doi.org/10.1016/j.bpobgyn.2011.04.006

[7] Cotran, R.S., Kumar, V. and Collins, T. (2000) Robbins Patología Estructural Y Funcional. Mcgraw-Hill Interamericana, Madrid.

[8] Ogden, G.R. (1997) The Future Role for Oral Exfoliative Cytology-Bleak or Bright? Oral Oncology, 33, 2-4. https://doi.org/10.1016/S0964-1955(96)00047-4

[9] Dabelsteen, E., Roed-Petersen, B., Smith, C.J. and Pindborg, J.J. (1971) The Limitations of Exfoliative Cytology for the Detection of Epithelial Atypia in Oral Leukoplakias. British Journal of Cancer, 25, 21-24.

[10] Folsom, T.C., White, C.P., Bromer, L., Canby, H.F. and Garrington, G.E. (1972) Oral Exfoliative Study: Review of the Literature and Report of a Three-Year Study. Oral Surgery, Oral Medicine, Oral Pathology, 33, 61-74.

https://doi.org/10.1016/0030-4220(72)90209-5

[11] Diniz-Freitas, M., Garcia-Garcia, A., Crespo-Abelleira, A., Martins-Carneiro, J.L. and Gandara-Rey, J.M. (2004) Applications of Exfoliative Cytology in the Diagnosis of Oral Cancer. Medicina Oral: Organo Oficial de la Sociedad Espanola de Medicina Oral Y de la academia Iberoamericana de Patologia Y Medicina Bucal, 9, 355-361.

[12] Davey, E., Barratt, A., Irwig, L., Chan, S.F., Macaskill. P., Mannes, P. and Saville, A.M. (2006) Effect of Study Design and Quality on Unsatisfactory Rates, Cytology Classifications, and Accuracy in Liquid-Based versus Conventional Cervical Cytology: A Systematic Review. Lancet, 367, 122-132. https://doi.org/10.1016/S0140-6736(06)67961-0

[13] Payne, N., Chilcott, J. and Mcgoogan, E. (2000) Liquid-Based Cytology for Cervical Screening. Cytopathology, 11, 469-470. https://doi.org/10.1046/j.1365-2303.2000.00291.x

[14] Singh, V.B., Gupta, N., Nijhawan, R., Srinivasan, R., Suri, V. and Rajwanshi, A. (2015) Liquid-Based Cytology versus Conventional Cytology for Evaluation of Cervical Pap Smears: Experience from the First 1000 Split Samples. Indian Journal of Pathology and Microbiology, 58, 17-21. https://doi.org/10.4103/0377-4929.151157

[15] Sahin, D., Yilmazbayhan, D., Firat, P., Hacisalihoglu, U.P., Kirimlioglu, S.H., Celenk, E. and Arslan, R. (2017) Comparison of Conventional Cytology and Surepath in Split Thyroid Fine Needle Aspiration Materials. Cytopathology, 28, 291-298. https://doi.org/10.1111/cyt.12430

[16] Park, G.S., Lee, S.H., Jung, S.L. and Jung, C.K. (2015) Liquid-Based Cytology in the Fine Needle Aspiration of Parathyroid Lesions: A Comparison Study with the Conventional Smear, Thinprep, and Surepath. International Journal of Clinical and $E_{X-}$ perimental Pathology, 8, 12160-12168.

[17] Kobayashi, T.K., Ueda, M., Nishino, T., Terasaki, S. and Kameyama, T. (1998) Brush Cytology of Herpes Simplex Virus Infection in Oral Mucosa: Use of the Thinprep Processor. Diagnostic Cytopathology, 18, 71-75. https://doi.org/10.1002/(SICI)1097-0339(199801)18:1<71::aID-DC12>3.0.CO;2-6 
[18] Maksem, J.A. and Weidmann, J. (2001) Specialized Preparative Devices Are Not Needed for Liquid-Based, Thin-Layer Cytology: An Alternate Manual Method Using a Metastable Alcoholic Gel. Diagnostic Cytopathology, 25, 262-264. https://doi.org/10.1002/dc.2051

[19] Mollaoglu, N., Wilson, M. J. and Cowpe, J.G. (2001) Extraction of DNA from Oral Cytological Samples by Scraping and Smear Method Suitable for Restriction Site Mutation analysis: A Pilot Study. Diagnostic Cytopathology, 25, 83-85. https://doi.org/10.1002/dc.2009

[20] Jajodia, E., Raphael, V., Shunyu, N.B., Ralte, S., Pala, S. and Jitani, A.K. (2017) Brush Cytology and Agnor in the Diagnosis of Oral Squamous Cell Carcinoma. Acta Cytologica, 61, 62-70. https://doi.org/10.1159/000451050

[21] Kujan, O., Pemberton, M.N., Schwarz, M. and Sloan, P. (2018) Evaluation of an Innovative Oral Brush for Potential Applications Using Liquid Based Cytology. Journal of Oral Science, 60, 45-50.

[22] Macey, R., Walsh, T., Brocklehurst, P., Kerr, A.R., Liu, J.L.Y. and Lingen, M.W (2015) Diagnostic Tests for Oral Cancer and Potentially Malignant Disorders in Patients Presenting with Clinically Evident Lesions. The Cochrane Database of Systematic Reviews, No. 5, Article No. CD010276. https://doi.org/10.1002/14651858.CD010276.pub2

[23] Allegra, S.R., Broderick, P.A. and Corvese, N. (1973) Oral Cytology. Seven Year Oral Cytology Screening Program in the State of Rhode Island. Analysis of 6448 Cases. Acta Cytologica, 17, 42-48.

[24] Dolens, E.S., Nakai, F.V.D., Santos, P., José, L. and Alborghetti, N.G. (2013) Cytopathology: A Useful Technique for Diagnosing Oral Lesions? A Systematic Literature Review. Diagnostic Cytopathology, 41, 505-514. https://doi.org/10.1002/dc.22875

[25] Mehrotra, R., Gupta, A., Singh, M. and Ibrahim, R. (2006) Application of Cytology and Molecular Biology in Diagnosing Premalignant or Malignant Oral Lesions. $\mathrm{Mo}$ lecular Cancer, 5, Article No. 11. https://doi.org/10.1186/1476-4598-5-11

[26] King, O.H.J. and Coleman, S.A. (1965) Analysis of Oral Exfoliative Cytologic Accuracy by Control Biopsy Technique. Acta Cytologica, 9, 351-354.

[27] Stahl, S.S., Sandler, H.C. and Cahn, L.R. (1964) The Significance of Dyskaryotic Cells in Exfoliative Cytology. Acta Cytologica, 8, 73-79.

[28] Mehta, F.S., Daftary, D.K. and Sahiar, B.E. (1970) A Correlative Histocytological Study of Epithelial Atypia in Leukoplakic and Submucous Fibrosis Lesions amongst Indian Villagers in a Mass Screening Programme. Indian Journal of Cancer, 7, 18-23.

[29] Mehta, F.S., Sahiar, B.E., Daftary, D.K., Gupta P.C. and Pindborg, J.J. (1972) A Correlative Histocytological Study of Carcinoma and Epithelial Atypia of the Palate among Indian Reverse Smokers. British Journal of Cancer, 26, 230-233. https://doi.org/10.1038/bjc.1972.31

[30] Mollaoglu, N., Cowpe, J.G. and Walker, R. (2001) Quantitative Cytomorphologic Analyses of Papanicolaou-Stained Smears from Oral Lichen Planus. Analytical and Quantitative Cytology and Histology, 23, 118-122.

[31] Bancroft, J.D. and Stevens, A. (1990) Theory and Practice of Histological Techniques. Churchill Livingstone, London.

[32] Kuyama, K., Matsumoto, T., Morikawa, M., Fukatsu, A., Ichimura, M., Wakami, M., Fukumoto, M., Kato, T. and Yamamoto, H. (2013) Morphometrical Findings among Dysplasias of Oral, Cervical and Bronchial Regions. Open Journal of Stomatology, 3, 215-222. https://doi.org/10.4236/ojst.2013.32037 
[33] Kahn, M. A. (2001) Oral Exfoliative Cytology Procedures: Conventional, Brush Biopsy and Thinprep. The Journal of the Tennessee Dental association, 81, 17-20.

[34] Karnon, J., Peters, J., Platt, J., Chilcott, J., Mcgoogan, E. and Brewer, N. (2004) Liquid-Based Cytology in Cervical Screening: An Updated Rapid and Systematic Review and Economic Analysis. Health Technology Assessment, 8, 1-78. https://doi.org/10.3310/hta8200

[35] Hayama, F.H., Motta, A.C.F., Silva, A.P.G. and Migliari, D.A. (2005) Liquid-Based Preparations versus Conventional Cytology: Specimen Adequacy and Diagnostic Agreement in Oral Lesions. Medicina Oral, Patologia Oral y Cirugia Bucal, 10, 115-122.

[36] Delavarian, Z., Mohtasham, N., Mosannen-Mozafari, P., Pakfetrat, A., Shakeri, MT. and Ghafoorian-Maddah, R. (2010) Evaluation of the Diagnostic Value of a Modified Liquid-Based Cytology Using Oralcdx Brush in Early Detection of Oral Potentially Malignant Lesions and Oral Cancer. Medicina Oral, Patologia Oral y Cirugia Bucal, 15, e671-676. https://doi.org/10.4317/medoral.15.e671

[37] Osaka, R., Hayashi, K., Onda, T., Shibahara, T. and Matsuzaka, K. (2019) Evaluation of Liquid Based Cytology for Tongue Squamous Cell Carcinoma: Comparison with Conventional Cytology. The Bulletin of Tokyo Dental College, 60, 29-37.

[38] Singh, P., Rohilla, M. and Dey, P. (2016) Comparison of Liquid-Based Preparation and Conventional Smear of Fine-Needle Aspiration Cytology of Lymph Node. Journal of Cytology, 33, 187-191. https://doi.org/10.4103/0970-9371.190444

[39] Sharma, S., Ahluwalia, C., Singh, M. and Mandal, A.K. (2018) Diagnostic Utility and Efficacy of Conventional versus Surepath Liquid-Based Cytology in Head and Neck Pathology: A Study in an Indian Tertiary Care Hospital. Iranian Journal of Pathology, 13, 188-195. https://doi.org/10.30699/ijp.13.2.188 